\title{
ENERGY SCAVENGING IN A VEHICLE'S EXHAUST SYSTEM
}

\author{
Kamil Lubikowski, Stanisław Radkowski, Krzysztof Szczurowski, Michał Wikary
}

\author{
Warsaw University of Technology, Institute of Vehicles \\ Narbutta Street 84, 02-524 Warsaw, Poland \\ tel.: +4822 2348118,fax: +48222348121 \\ e-mail:k.lubikowski@mechatronika.net.pl,ras@mechatronika.net.pl, \\ kszczur@simr.pw.edu.pl,m.wikary@mechatronika.net.pl
}

\begin{abstract}
Present- day development of power transmission systems, especially the ones based on combustion engines, is trying to cope with the issue of improving the energy efficiency of energy processing systems. One of the directions is to use the techniques of thermal energy recovery from an engine's exhaust system. Vast part of the energy produced while burning the air-fuel mixture is lost in the cooling and exhaust systems. Research in this area was conducted by numerous teams, both abroad and in Poland, while focusing on use of Peltirea cells. The results of their research demonstrated small efficiency of these cells. In this paper, the authors have focused on modifications of the exhaust system in order to improve heat exchange between the exhaust system's elements and TEG.

The research was conducted while using the ECOTEC 1.8 litre engine from Opel, the X18XE model. The engine was installed in a testbed, in the mechatronic lab at the Faculty of Automotive and Construction Machinery Engineering (SIMR) of Warsaw University of Technology. Spartan HE923 radiators were installed on the cold end of the module. The paper presents the results of the research related to interworking of TEG's with the exhaust system's heat-generating elements of various shapes.

The paper reviews the energy efficiency of TEG depending on diverse parameters of gas flow. A parallel system has been assumed (controlled stream and pressure of the flowing exhaust gases without any interference as regards the speed of the of combustion engine).

The factor-related experiment accounts for the influence that the pressure and temperature difference, depending on the volume and discharge of exhaust fumes, have on the efficiency of TEG for the same temperature.

The results of the experiment are presented in the last section of the article.
\end{abstract}

Keywords: cogeneration of energy, exhaust system, thermoelectric generator

\section{Introduction}

The article deals with laboratory research involving an actual combustion engine installed in the testbed in a lab. As is known based from the heat balance of a combustion engine, there is no possibility of converting the entire heat energy obtained from burning the fuel blend into mechanical work. It is only around $25-40 \%$ of the heat supplied to the engine that is converted. The rest of the heat, $60-75 \%$, goes away with the combustion gases or is removed by the coolant. It is anticipated that recovery of $6 \%$ of the energy lost could reduce fuel consumption by $10 \%$ [1]. In addition, part of the mechanical energy, obtained by conversion from heat, is used for powering the systems inside the engine, such as the timing gear system or the pump in the cooling system, etc.

We have developed a heat balance $[2,5]$ to illustrate the way in which the heat supplied to the engine has been used:

$$
Q_{d}=Q_{e}+Q_{c h}+Q_{w}+Q_{n s}+Q_{o t} \quad\left[\frac{k J}{s}\right],
$$

where:

$Q_{d}$ - the total amount of heat supplied to the engine during one second,

$Q_{e}$ - useful heat, i.e. the amount of heat, which has been converted during one second into effective work, 
$Q_{w}$ - exhaust loss, i.e. the amount of heat which is removed together with exhaust fumes during one second,

$Q_{c h}-$ cooling loss, i.e. the amount of heat which is removed with the cooling agent during one second,

$Q_{n s}-$ combustion loss, i.e. the amount of heat lost during one second as a result of incomplete combustion,

$Q_{o t}$ - heat loss to the environment, i.e. the amount of heat emitted to the environment during one second, without involvement of cooling agents.

The element responsible for mechanical loss in an engine is missing in the above heat balance equation. Part of mechanical loss (the heat generated by friction of a piston against the surface of the cylinder) is included in the cooling-related loss $Q_{c h}$, while the remaining part of such loss is contained in the $Q_{o t}$ component. By diving both sides of the equation by $Q_{d}$ and multiplying them by 100 we will arrive at the heat balance expressed in percent:

$$
100 \%=q_{e}+q_{c h}+q_{w}+q_{n z}+q_{o t},
$$

Relevant components in the presented relationships are most often determined in the following way:

- the heat which is supplied to the engine is calculated based on fuel consumption during one second:

$$
Q_{d}=G_{e} \cdot W_{u},
$$

where:

$G_{e}-$ fuel consumed during one second,

$W_{u}-$ fuel's calorific value,

- heat converted into effective work:

$$
Q_{e}=N_{e},
$$

- the heat lost via the cooling system is calculated based on the mass intensity of flow of the coolant (liquid or air) and the change of its temperature:

$$
Q_{c h}=G_{c h} \cdot c \cdot\left(T_{c h w}-T_{c h d}\right),
$$

where:

$G_{c h}$ - mass flow intensity (flux) of the coolant,

c - specific heat of the coolant,

$T_{c h d}$ - mean temperature of the coolant at the inlet,

$T_{c h w}$ - mean temperature of the coolant at the outlet,

- the outlet (exhaust) loss, i.e. the amount of the heat removed during one second with the exhaust gases:

$$
Q_{w}=M_{s p} \cdot G_{e} \cdot c_{s p} \cdot\left(T_{w}-T_{o}\right)
$$

where:

$M_{s p}$ - the mass of moist exhaust gases generated from burning $1 \mathrm{~kg}$ of fuel,

$G_{e}$ - fuel consumption during one second,

$c_{s p}$ - mean molal heat capacity of moist exhaust gases in the temperature range from $T_{o}$ to $T_{w}$,

$T_{o}$ - mean temperature of the exhaust gases leaving the engine,

$T_{w}$ - ambient temperature.

The biggest problems have been encountered while trying to determine the last two components of the heat balance - heat loss during combustion process and heat loss to the environment. Heat loss means the heat lost as a result of incomplete combustion of fuel. Heat loss to the environment, in turn, constitutes the remaining part of the heat balance and includes the heat loss which is impossible to be captured, such as the heat which is emitted or given off to the environment as a result of conduction, the heat generated by friction in the engine's mechanisms 
etc. To simplify the process, the components $Q_{n s}$ and $Q_{o t}$ are often determined jointly, after the remaining components of the heat balance have been calculated.

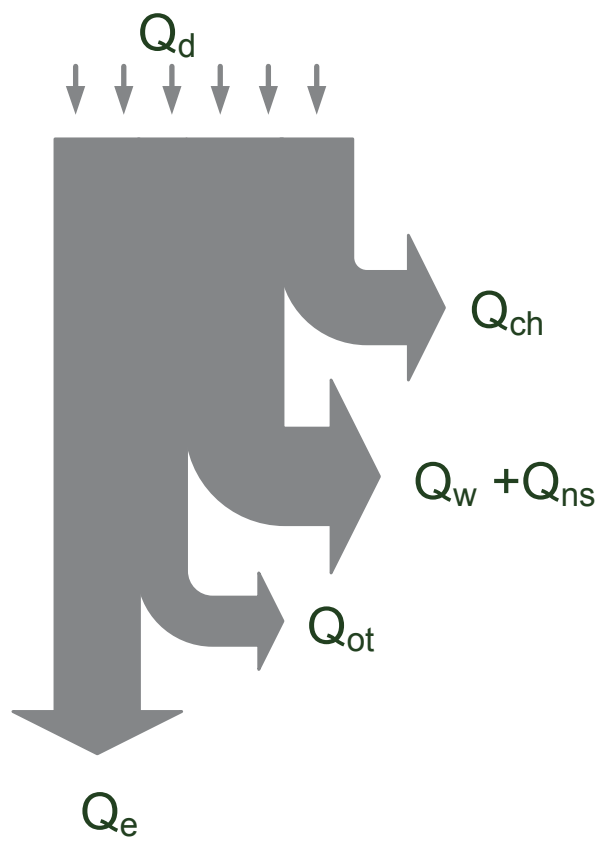

Fig. 1. Sankey graph - heat balance of a combustion engine [1]

The value of the exhaust-related and cooling loss depends on the operational conditions as well as on the structure of an engine. Cooling loss decreases as the rotational speed of an engine increases since the time during which the hot gases are in contact with the cylinder walls is shorter (for small power and constant rotational speed), thus the cooling loss decreases while the exhaustrelated loss increases.

The results of the analysis conducted this way are often presented in a graphical form, as a Sankey graph. The exemplary presentation of this can be seen in Fig. 1. [quoting K. Szczurowski - 5].

Apart from the thermal efficiency of the exhaust system, it is also the method adopted for examining the way the stream of exhausted gases is controlled that is also an important feature, since it enables a defined temperature to be maintained, thus preventing damage to the TEG used for the tests.

At the same time the temperature of the examined surface, and thus the temperature of the exhaust gases, is affected by changes of the volume of the flowing gases. No research has been conducted yet as regards the influence of change of the volume of gases, i.e. from the volume for the original cross-section of an exhaust pipe to the volume for a smaller or a bigger cross-section of the pipe. Based on Clapeyron's equation, when the cross-section changes, the parameters of the gas should also change. To illustrate the situation, Clapeyron's equation is presented below for an ideal gas condition:

$$
p \cdot V=n \cdot R \cdot T
$$

where:

$\mathrm{p}$ - pressure of the ideal gas,

$\mathrm{V}$ - volume of the ideal gas,

$\mathrm{n}$ - number of moles of an ideal gas,

$\mathrm{R}$ - gas constant of the ideal gas,

$\mathrm{T}$ - temperature of the ideal gas.

Assuming that the exhaust gases are an ideal gas, that we know the number of moles and the universal gas constant " $R$ ", we can conclude that the parameters will not change. Thus At this 
point the exhaust fumes are described by only three variables: pressure " $p$ ", volume "V" and temperature " $T$ ". If the volume increases, then the values of gas pressure or temperature should also change. Thus if the pressure does not decrease, then one should expect increase of temperature. At the same, if no change of temperature is observed, then one should expect the pressure to decrease.

In their publication [3] the authors described the research as well as the computer simulations of flow of the exhaust fumes' stream through different cross-sections (triangular, rectangular, hexagonal). In spite of a big difference between the cross section of an exhaust pipe and the examined, additional element, the scientists from India observed increased stress with a significant temperature gradient. At the same time the authors noted that the maximum temperature of the hot side of TEG was $220^{\circ} \mathrm{C}$.

In our research we used TEG from LAIRD for which the manufacturer anticipated the maximum temperature of the hot side of $200^{\circ} \mathrm{C}$. At the same time, for the TEG research it was assumed that the cross-section of an exhaust pipe should be square rather than round and the dimensions of the exhaust pipe's walls were calculated. A rectangular cross-section was used for a parallel system which was used for controlling the temperatures.

Dimensions of a circular section:

$\mathrm{r} \sim 23 \mathrm{~mm}$, where the area of the section is $\mathrm{P}_{\mathrm{o}}=1661.9 \mathrm{~mm}^{2}$.

A square section has been calculated:

$\mathrm{a}=40 \mathrm{~mm}$, where the area of the section is $\mathrm{P}_{\mathrm{kw}}=1600 \mathrm{~mm}^{2}$.

A rectangular section has been calculated:

$\mathrm{a}=30 \mathrm{~mm}, \mathrm{~b}=55 \mathrm{~mm}, \quad$ where the area of the section is $\mathrm{P}_{\mathrm{pr}}=1650 \mathrm{~mm}^{2}$.

The square section, for a $40 \times 40$ pipe, was used in the research.

Supercharging systems are another good example of a system for scavenging energy from waste processes [4, 5]. Apart from the obvious advantages, such as increase of intake pressure, state-of-the-art devices offer the possibility of energy scavenging which can be seen on the example of a BMW patent.

The concept of an "electric" turbocharger (Fig. 2) must not be treated literally since as a matter of fact it is a kind of a hybrid - a combination of a standard method of operation as a compressor and of an electric machine. A traditional turbocharger is powered by exhaust gases. Its rotational speed increases together with the growth of intensity of exhaust gases, whose volume increases along with the increasing engine speed/engine load. At low speed we come across the so-called effect of a "turbo lag". One of the solutions to eliminate it is an electrical motor which powers the turbine at low engine speed. Once the turbine reaches high speed again, the clutch (6), proposed by BMW, will once again couple it with the compressor.

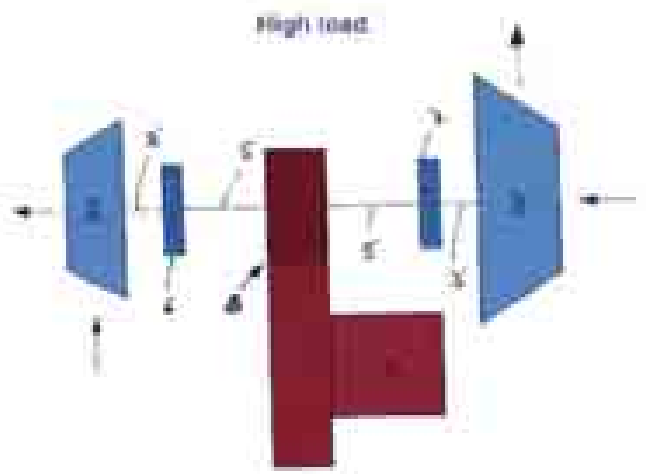

Fig. 2. Schematic diagram of a turbocharger patented by BMW: turbine shafts (2') compressor shafts (3'), clutches $(6,7)$, (5) an electric motor shaft, (4) an electric motor which is also an alternator, a turbine (2), a compressor (3) [3]

What is even more interesting, the electrical motor plays yet another role at this moment. To prevent the turbine from operating at too high speeds (in the traditional solution it is the release 
valve that does the job), the motor works as an alternator, by braking the turbine shaft accordingly. The clutches in a turbocharger are controlled by relevant sensors. BMW uses this solution in its $550 \mathrm{Xd}$ model, among others, while achieving $381 \mathrm{BHP}$ and maximum torque of $740 \mathrm{Nm}$ from a Diesel engine with a capacity of $3000 \mathrm{cc}$.

Another concept of the authors of this article is to have a turbine with a generator installed directly in a vehicle's exhaust system and to test the possibility of energy scavenging and the influence that the solution has on the stream of exhaust gases. There are future plans of testing this in the test bed at the Faculty of Automotive and Construction Machinery Engineering (SIMR) of Warsaw University of Technology.

\section{Description of the test bed.}

The research was carried out at a test bed with the ECOTEC X18XE engine at the Faculty of Automotive and Construction Machinery Engineering of Warsaw University of Technology, in the Integrated Laboratory of the Mechatronics System of Vehicles and Construction Machinery.

We used disjoint elements of the entire exhaust system in which we examined the temperatures, starting from measurement points at the exhaust manifold all the way to the final muffler, while doing this to locate the heating element for the purpose of research. Initially the test bed contained a "handicraft" element, where the element with the round cross-section was replaced by one with a square cross-section, as shown in Fig. 3.

The Spartan HE923 radiator with a fan, which normally serves the purpose of cooling the processors in computers, was used for the research.

The radiator collected thermal energy radiating from the cold side of the heated TEG. A Lutron TM-909 pyrometer and the Kazemaster Pro system, used for controlling the temperatures on a computer motherboard as well as controlling the speed of the cooling fans, were used to read the prevailing temperatures.

Kazemaster set consists of a 6-channel electronic controller which enables simultaneous change of speeds of two fans and reading of temperatures from two temperature sensors (thermocouples). A universal multi-purpose meter was used for reading the voltage at the ends of TEG.

A Peltier cell was attached to the exhaust pipe's surface while using silicon. Before the Peltier cell was installed, the heat-collecting radiator, mentioned earlier, was first installed on the cell's cold side. A multi-purpose meter was connected to the TEG terminals.

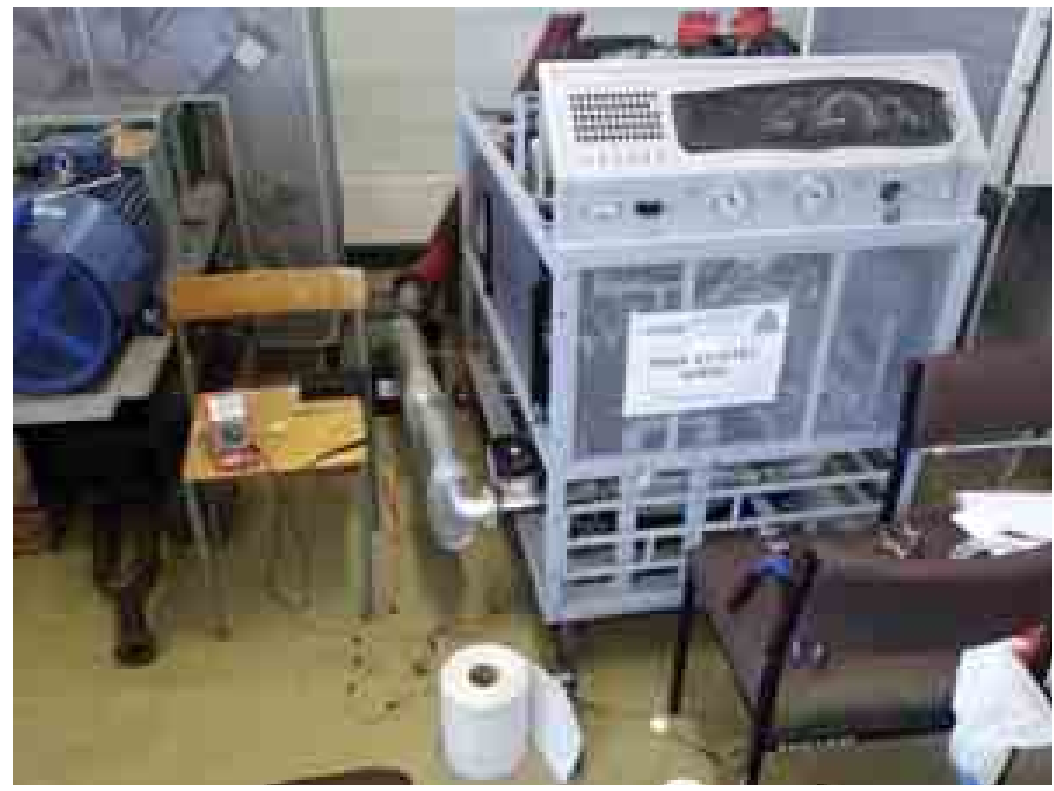

Fig. 3. Photo of a testbed with the ECOTEC X18XE engine 


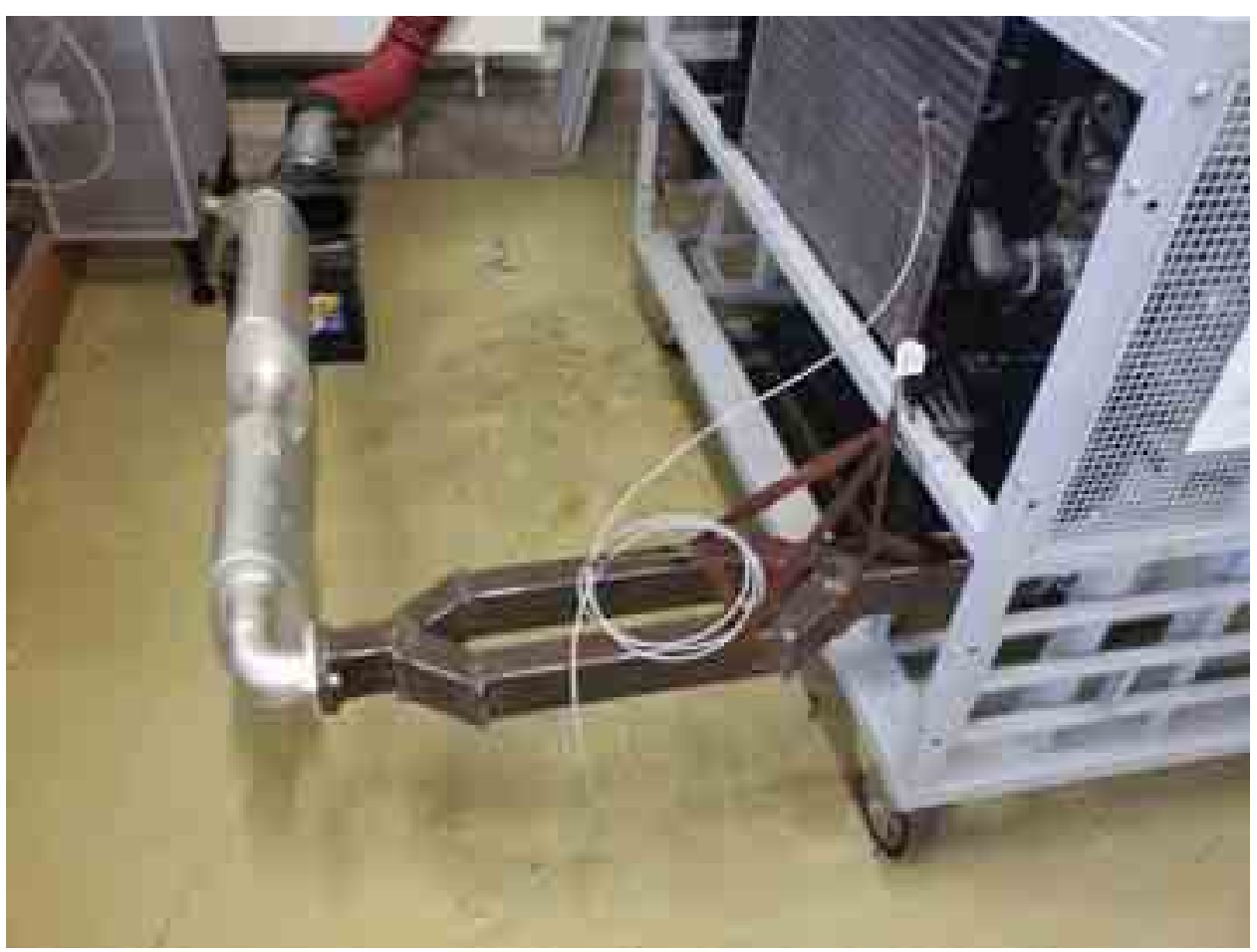

Fig. 4. Photo of the test bed with a rectangular pipe. ECOTEC X18XE engine

The meter was reading the values of the voltage generated by TEG. Time was measured with the use of a chronometer, with voltage changes being measured at the same time. The measurements were performed for two states: for the engine operating at neutral gear (idle), at $800 \mathrm{rpm}$, and for constant speed of $2000 \mathrm{rpm}$.

Then, once the research was conducted while using a square pipe, a "handicraft" made element made of two pipes with a rectangular cross-section was installed in which we measured the pressure in the exhaust system as well as the influence that the temperature of exhaust gases had on the surface of the system, which we did by way of controlling the stream of exhaust gases. The next item presents the results of the research related to the temperature and the decrease in time of the voltage depending on temperature. Because of the temperature, for our tests we selected the section between the catalytic reactor and the mufflers.

\section{Results of the research.}

At the moment the tests began (when the engine was started at the test bed), the exhaust fumes started heating the exhaust system which removes exhaust fumes from the engine, thus causing sudden growth of temperature of the pipe. Thus the results were being recorded in time. Initially the temperature gradient was so high, between the hot side of TEG and the cold side of TEG, that $3.28 \mathrm{~V}$ was recorded.

At the moment when the engine started operating without any load, at idle gear with $800 \mathrm{rpm}$ (start of tests):

We noted leap of voltage:

$\mathbf{U}=\mathbf{3 . 2 8 V}$ (the result after 5 minutes);

$\mathbf{T}_{\mathbf{H}}=$ initially $26^{\circ} \mathrm{C}$, increased to as much as $90^{\circ} \mathrm{C}$ (change during 5 minutes);

$\mathbf{T}_{\mathbf{C}}=$ initially $27^{\circ} \mathbf{C}$, increased to as much as $\mathbf{5 1}^{\circ} \mathrm{C}$ (change during 5 minutes).

After 30 minutes:

$$
\begin{aligned}
& \mathrm{U}=1.90 \mathrm{~V} ; \\
& \mathrm{T}_{\mathrm{H}}=88^{\circ} \mathrm{C} ; \\
& \mathrm{T}_{\mathrm{C}}=54^{\circ} \mathrm{C} \text {. }
\end{aligned}
$$


The voltage at TEG terminals finally stabilized at around $\mathbf{U}=\mathbf{1 . 4 V}$ when only the radiator without the radiator fan was used. Every time the fan on the radiator was activated or revolutions of the engine increased, the voltage at TEG terminals increased rapidly.

After 10 minutes more:

$$
\begin{aligned}
& U=1.61 \mathrm{~V} ; \\
& T_{H}=83^{\circ} \mathrm{C} ; \\
& T_{C}=53^{\circ} \mathrm{C} \text {. }
\end{aligned}
$$

After 10 minutes more:

$$
\begin{aligned}
\mathbf{U} & =1.4 \mathrm{~V} ; \\
\mathrm{T}_{\mathrm{H}} & =72^{\circ} \mathrm{C} ; \\
\mathrm{T}_{\mathrm{C}} & =47^{\circ} \mathrm{C} .
\end{aligned}
$$

Then upon determining the operating condition at which no voltage reduction was observed, we changed the operating conditions. In this case the speed was increased to $2000 \mathrm{rpm}$. This situation changed the parameters of electrical energy scavenging by simulating initial operation of an engine under a load. Growth of temperature at measurement points was observed.

While the rotational speed increased:

$$
\begin{aligned}
\mathbf{U} & =2.5 \mathrm{~V} ; \\
\mathrm{T}_{\mathrm{H}} & =98^{\circ} \mathrm{C} ; \\
\mathrm{T}_{\mathrm{C}} & =50^{\circ} \mathrm{C} .
\end{aligned}
$$

After 10 minutes of operation with the set speed of 2,000 rpm.:

$$
\begin{gathered}
\mathrm{U}=3.12 \mathrm{~V} ; \\
\mathrm{T}_{\mathrm{H}}=120^{\circ} \mathrm{C} ; \\
\mathrm{T}_{\mathrm{C}}=62^{\circ} \mathrm{C} .
\end{gathered}
$$

The maximum value of voltage at the cell's terminals, which was observed while performing temperature and voltage measurements, reached $\mathrm{U}=3.15 \mathrm{~V}$. Then the temperature of constant flow steadied, which led to the decrease of the temperature gradient, and decreasing voltage was observed at the same time.

After another 10 minutes of operation with the set speed of 2,000 rpm:

$$
\begin{gathered}
\mathrm{U}=3.12 \mathrm{~V} ; \\
\mathrm{T}_{\mathrm{H}}=127^{\circ} \mathrm{C} ; \\
\mathrm{T}_{\mathrm{C}}=67^{\circ} \mathrm{C} .
\end{gathered}
$$

Moreover the prevailing temperatures in the exhaust system were examined.

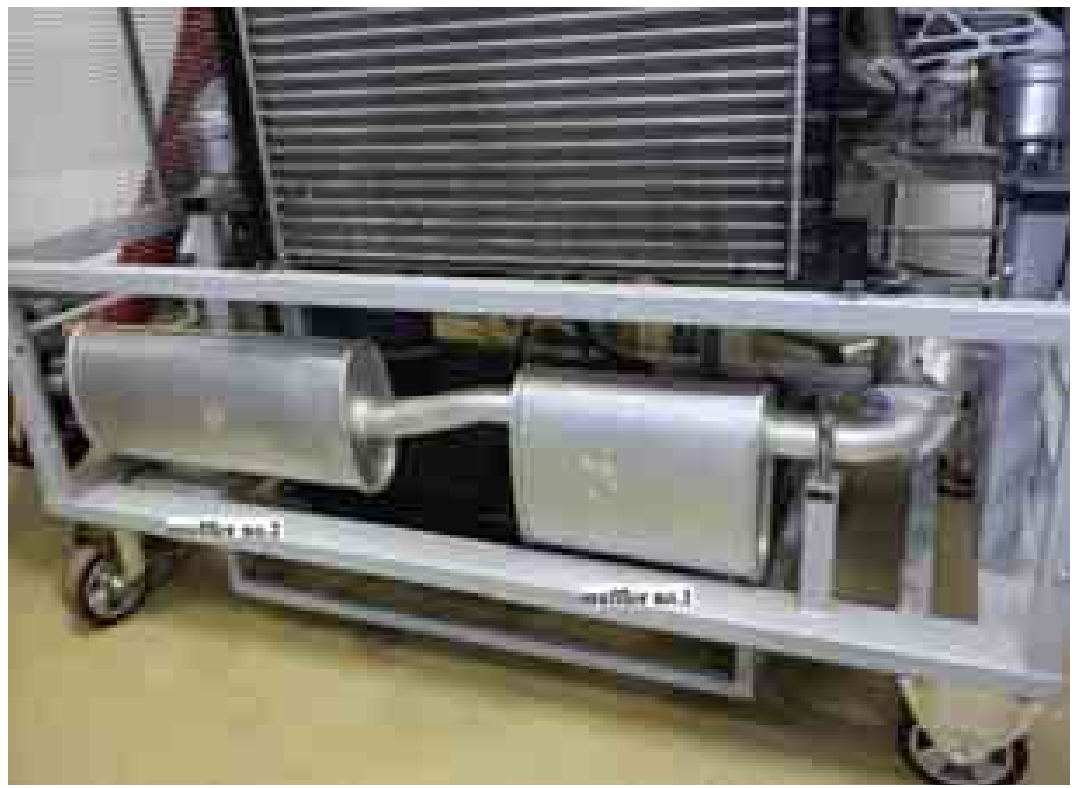

Fig. 5. Photo of a test bed with the mufflers marked 


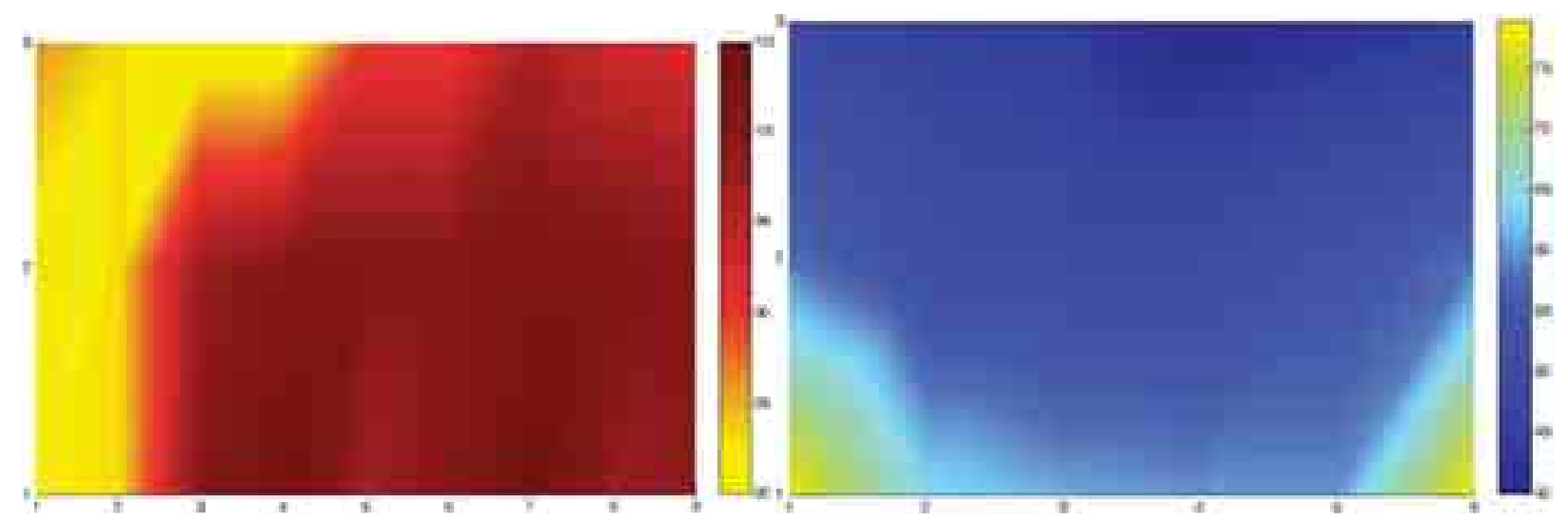

Fig. 6. Photo of temperature distribution: in muffler 2 on the left-hand side and in muffler 1 on the right-hand side

Then the prevailing temperatures on the surface of the exhaust system were checked. The temperatures prevailing in the system are presented in the below figures.

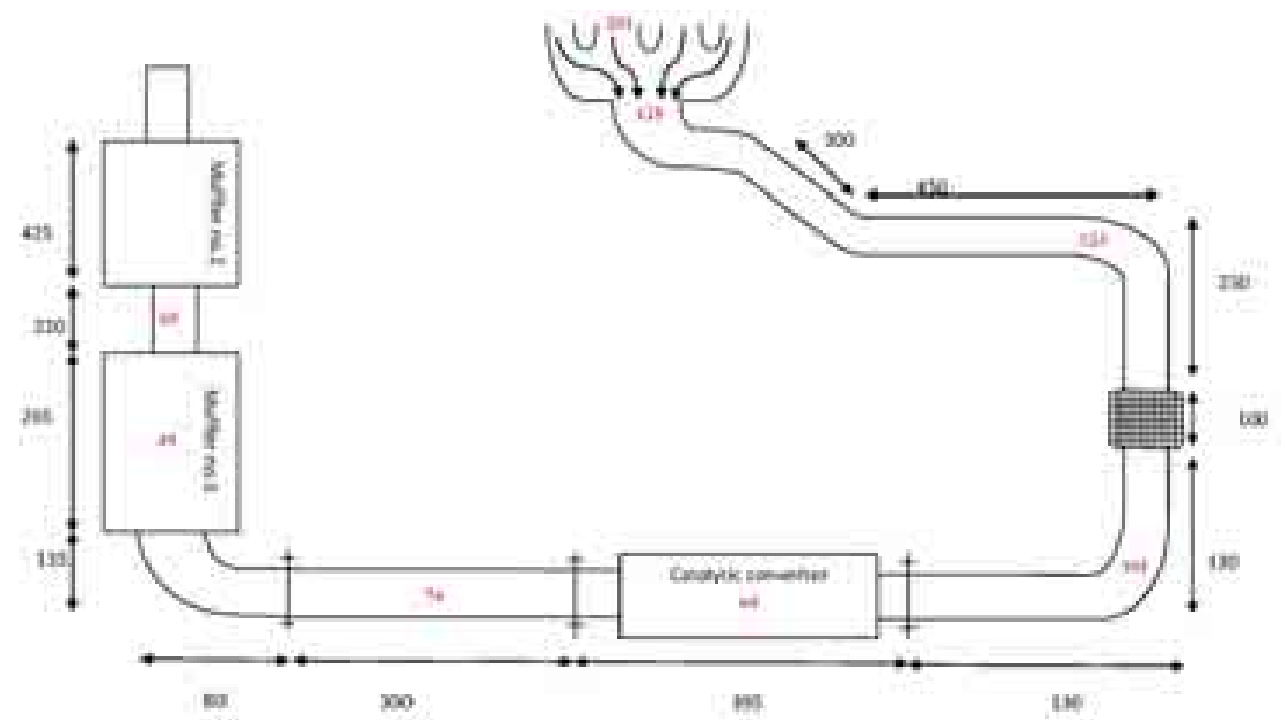

Fig. 7. A figure presenting the temperatures prevailing at the surface of the exhaust system (red colour) for engine speed of $800 \mathrm{rpm}$

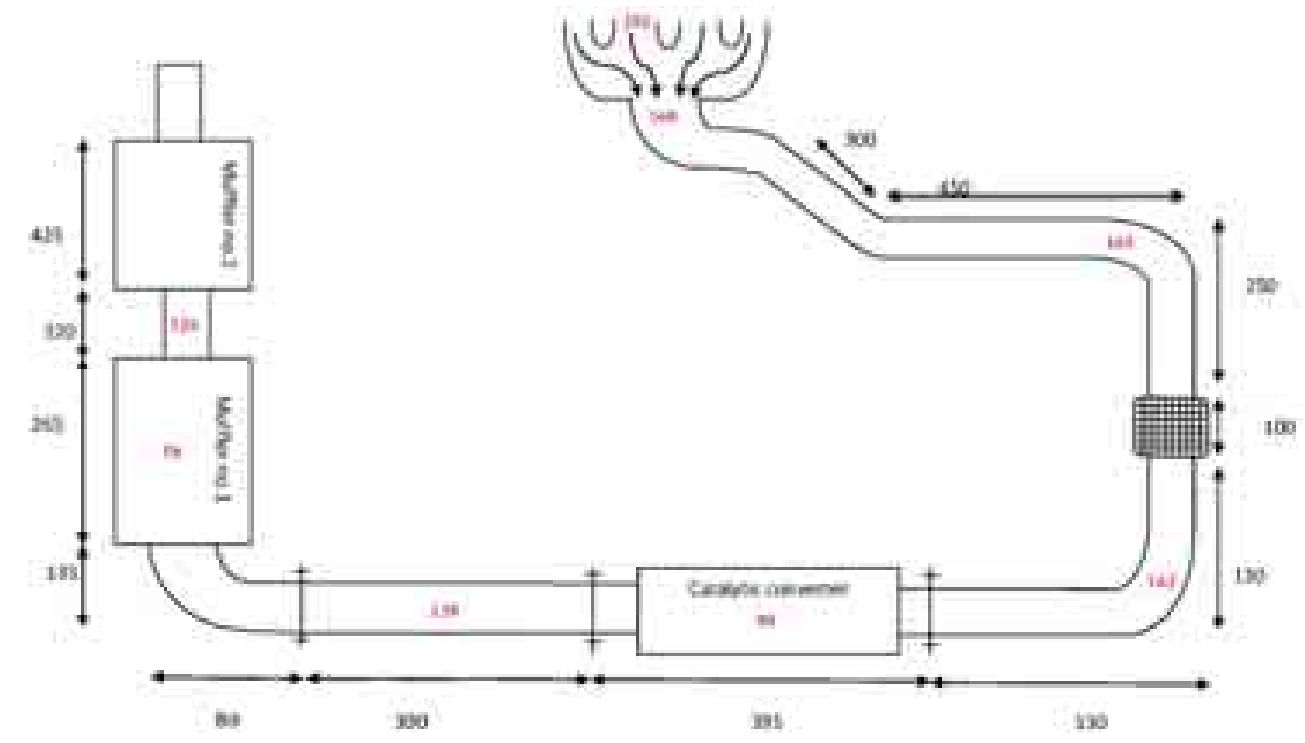

Fig. 8. The figure presents the temperatures prevailing on the surface of the exhaust system (red colour) at $2000 \mathrm{rpm}$ 


\section{Conclusions}

Figure 6, showing the distribution of temperatures on the muffler's surface, demonstrates that the temperature on the surface of the first muffler is substantially lower than the temperature on the surface of the second muffler. It has been confirmed by temperature measurements on the surface of the entire exhaust system, as presented in Fig. 7 and Fig. 8. The temperatures had to be examined in order to choose a place where TEG would be installed. As can be seen from Fig. 7 and 8, the surface temperature changed significantly at the place of the tests when only the engine speed increased, without any load. One may expect even bigger values once the engine works under a load at higher speeds (RPM values). It is important that the temperature of $200^{\circ} \mathrm{C}$ is not exceeded as it could damage TEG.

The most important finding is the determination, during the tests, of the smallest value of the voltage in the range of $1.4 \mathrm{~V}$. Further simulations and calculations have to rely on this value of voltage. At the same time, to be able to determine the useful power which can be recovered, load tests must be performed at the test bed. To this end, a receiver must be connected to TEG terminals. Such tests will be performed in the future at the Faculty of Automotive and Construction Machinery Engineering (SIMR) of Warsaw University of Technology.

\section{References}

[1] Wojciechowski, K., Merkisz, J., Fuć, P., Lijewski, P., Schmidt, M., Zybała, R., Study of recovery of waste heat from exhaust of automotive engine, 5th European Conference on Thermoelectrics, pp. 194-198, Odessa, Ukraine 2007.

[2] Kijewski, J., Silniki spalinowe (Combustion engines), WSiP, 1991.

[3] Kumar, C. R., Sonthalia, A., Goel, R., Experimental study on waste heat recovery from an internal combustion engine using thermoelectric technology, Termal Science, Vol. 15, No. 4, pp. 1011-1022, India 2011.

[4] http://autokult.pl/2011/11/04/bmw-opatentowalo-elektryczna-turbosprezarke.

[5] Szczurowski, K., Kogeneracja energii w zagadnieniu bilansu cieplnego silników spalinowych (Cogeneration of energy as an element of the heat balance of combustion engines), Zeszyty Instytutu Pojazdów 5(86), pp. 165-170, Warszawa 2011. 